\title{
Trihoney ameliorates hypercholesterolemia-induced epididymal histopathological changes in male rabbits
}

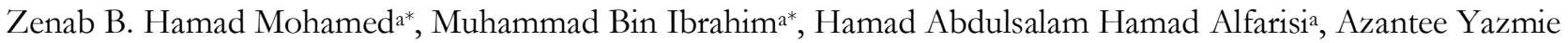 \\ Abdul Wahab ${ }^{b}$, Azliana binti Abd Fuaatc, Che Anuar Che Mohamadd

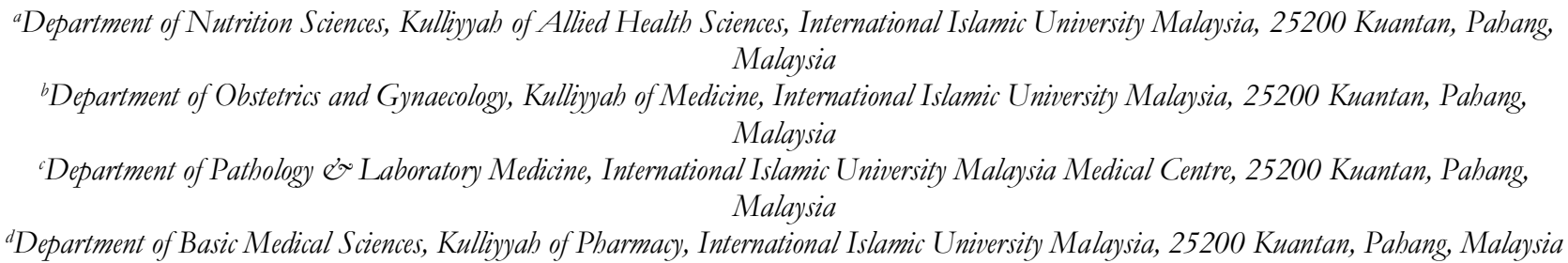

Received 4th November 2019 / Accepted 6th February 2020

\begin{abstract}
Hypercholesterolemia has been linked to weight change and histopathological alteration of male reproductive organs. The epididymis was suggested to be an early target of lipid-related infertility and can be dramatically affected by excess intake of a high cholesterol diet. On the other hand, the interest has been increased towards the use of honey as a prophylactic and therapeutic agent for various diseases. Therefore, the purpose of this study is to investigate the effects of Trihoney (a mixture of Trigona, Mellifera and Tualang) on epididymal weight change and histopathological alterations in hypercholesterolemic male rabbits and compare its effects with atorvastatin. Forty-eight mature male New Zealand white rabbits were divided into 6 groups. Two groups received standard rabbit pellet with 0 and $0.6 \mathrm{~g} / \mathrm{kg} /$ day of Trihoney respectively while the other four groups received $1 \%$ cholesterol diet with 0 , $0.3,0.6 \mathrm{~g} / \mathrm{kg} / \mathrm{day}$ of Trihoney, and $2 \mathrm{mg} / \mathrm{kg} /$ day of atorvastatin. After 12 weeks, the rabbits were sacrificed and the epididymides were harvested for evaluation of weight and histopathological changes. Administration of $1 \%$ cholesterol diet either alone or in combination with atorvastatin caused a significant reduction in the epididymal weight and epididymal atrophy. Supplementation of Trihoney particularly at the dose of $0.6 \mathrm{~g} / \mathrm{kg} /$ day improved epididymal weight, regained the normal architecture of the epididymal histology and increased the number of mature sperm inside the tubules of the epididymis. Based on these results, Trihoney exhibited its potential health benefit as a protective agent against epididymal weight reduction and histopathological alterations in hypercholesterolemic rabbits.
\end{abstract}

Keywords: atorvastatin, epididymis, histology, hypercholesterolemia, Trihoney

\section{INTRODUCTION}

Epididymis is a specialized organ of male reproductive system located behind each testis. It is a convoluted tubule divided into three parts; head (caput), body (corpus) and tail (cauda). It is lined by epithelial cells that have important secretory and absorptive activities. These activities create a luminal environment which is essential and responsible for enhancement of functional maturation of sperm and maintaining them immotile and viable before ejaculation

*Authors for correspondence: Zenab B. Hamad Mohamed and Muhammad Bin Ibrahim, Department of of Nutrition Sciences, Kuliyyah of Allied Health Sciences, International Islamic University Malaysia, 25200 Kuantan, Pahang, Malaysia. Email-zenab.B.zoubi@gmail.com, abumaisarah@iium.edu.my 
(Anderson et al., 2015; Sandella et al., 2012). Histopathological examination of the testes should be accompanied by the histopathological examination of the epididymides which provides an important information on testicular recent events (De Grava Kempinas \& Klinefelter, 2014). Organ weight is an important parameter that can give an idea about the physiology and histology of the organ (Creasy, 2001). Hypercholesterolemia has been linked to weight changes and histopathological alteration of male reproductive organs including the epididymis. It reduces epididymal weight (Alzubaidi \& Diwan, 2013) and reduces the height of the epithelial cells of caput and cauda of the epididymis (Bataineh \& Nusier, 2005). The epididymis was suggested to be an early target of lipid-related infertility and can be dramatically affected by excess intake of a high cholesterol diet (Ouvrier et al., 2011). On the other hand, the interest has been increased towards the use of honey as a prophylactic and therapeutic agent for various diseases as well as for improving and maintaining the overall wellbeing (Inoue et al., 2005; Nweze et al., 2016; Pyrzynska \& Biesaga, 2009). Trihoney is a mixture of three types of honey namely Trigona, Mellifera and Tualang at a specific ratio. This ratio produced the highest result of total phenolic content with consuming the minimum amount of each honey. It is a product developed by the Department of Nutrition Sciences, Kulliyyah of Allied Health Sciences, International Islamic University Malaysia (IIUM). It was optimized using Response Surface Methodology (RSM) of Design Expert Version 6.0 software (data not published yet). Hence, the aim of this study is to investigate the possible protective effects of Trihoney on epididymal weight change and histopathological alterations induced by hypercholesterolemia in male rabbits and compare its effects with atorvastatin as the most commonly used lipid lowering agent.

\section{MATERIALS AND METHODS}

\section{Animal}

Forty-eight male New Zealand white rabbits at the age of 5 months were used in this study. Their environment was maintained under controlled conditions of $15-21^{\circ} \mathrm{C}$ temperature, $45-65 \%$ humidity and 12-hours light/dark cycles. The rabbits were caged individually and they had free access to water and food throughout the experiment. The animal handling procedures, treatment and experimental protocols were approved by the International Islamic University Malaysia Institutional Animal Care and Use Committee (IACUC-IIUM), IIUM, Kuantan campus (No. of IACUC Approval: IIUM/ IACUC Approval/2017/(18)-2, and conformed to the guidelines for the Malaysian Code of Practice for the Care and Use of Animal for Scientific Purposes.

\section{Preparation of 1\% cholesterol diet}

One percent cholesterol diet was chosen and prepared according to the methods of Ibrahim et al. (2017) and Jorge et al. (2005) with some modifications. Ten grams of cholesterol powder (Nacalai-Tesque, Japan) were emulsified in $20 \mathrm{~mL}$ $(2 \%)$ of cholesterol-free extra virgin coconut oil (Certified Organic, Philippines). The emulsion was then poured onto 970 grams of rabbit pellet and mixed thoroughly. The high cholesterol diet was kept at room temperature. It was prepared twice weekly to prevent oxidative modification of the high cholesterol diet (Mohamed et al., 2017).

\section{Trihoney and atorvastatin doses}

Two different doses of Trihoney $(0.6 \mathrm{~g} / \mathrm{kg} /$ day and $0.3 \mathrm{~g} / \mathrm{kg} /$ day) were used in this experiment. The animal equivalent dose of Trihoney was calculated using rabbit $\mathrm{Km}$ factor according to Reagan-Shaw et al. (2007). The dose of atorvastatin used in this study was $2 \mathrm{mg} / \mathrm{kg} /$ day (Du et al., 2013). Atorvastatin was reconstituted in $1 \mathrm{~mL}$ of distilled water then administered orally (Song et al., 2014).

\section{Experimental design}

After an acclimatization period of 2 weeks, the rabbits were randomly divided into 6 groups $(n=8)$ and received different diets as follows: Control (C): standard rabbit pellet, $\mathrm{CH}$ : standard rabbit pellet with a daily oral dose of $0.6 \mathrm{~g} / \mathrm{kg} /$ day of Trihoney, HCD: 1\% cholesterol diet, DH1: 1\% cholesterol diet and a daily oral dose of 0.3 $\mathrm{g} / \mathrm{kg} /$ day of Trihoney, DH2: 1\% cholesterol diet and a daily oral dose of $0.6 \mathrm{~g} / \mathrm{kg} /$ day of Trihoney, DAt group: $1 \%$ cholesterol diet and a daily oral 
dose of $2 \mathrm{mg} / \mathrm{kg} /$ day of atorvastatin. Weights of the rabbits were measured once weekly (Soltani et al., 2013) and Trihoney and atorvastatin doses were adjusted accordingly. The whole duration of the experiment was 12 weeks (Ashrafi et al., 2013).

\section{Animal sacrificing and epididymides harvesting}

At the end of the 12 weeks and after the confirmation of hypercholesterolemia, the rabbits fasted overnight and euthanized using intramuscular injection of ketamine/ xylazine at a dose of $50 / 10 \mathrm{mg} / \mathrm{kg}$ body weight (Zhao et al., 2013) followed by exsanguination (Leary et al., 2013). Under complete clean conditions, a longitudinal incision was made through the abdominal cavity and pelvis. The testes and epididymides were immediately and carefully removed, rinsed with sterile physiologic sodium chloride, gently taken, separated from each other and weighed (Galaly et al., 2014). One epididymis from each rabbit was fixed in $10 \%$ neutral buffered formalin for histological examination (Creasy et al., 2008).

\section{Histological examination}

The fixed epididymides were processed and embedded in paraffin blocks. The blocks were then sectioned longitudinally into $4 \mu \mathrm{m}$ thick ribbons. The sections were subsequently stained with haematoxylin and eosin stain (H\&E) and Masson's Trichrome stain (Clin-Tech Limited, UK). The slides were viewed under a light microscope (Leica, Germany) and analysed for the microscopic features. The slides were scanned using Leica Aperio CS2 digital scanner. Photographs of the microscopic features were captured using Aperio ImageScope from Leica Biosystem version 12.4.0.5043.

\section{Histological measurements}

Measurements of epithelial height of caput and cauda of the epididymis and the large diameter of ductal lumens of the caput and cauda of the epididymis were calculated using Aperio ImageScope from Leica Biosystem version 12.4.0.5043.

\section{Statistical analysis}

Data were processed using the Statistical Package for the Social Sciences Version 21 (SPSS Inc., Chicago, Illinois, USA) program. The data were expressed as means and standard deviations. The data were normally distributed, therefore, oneway analysis of variance test (ANOVA) was used for data analysis followed by a post hoc test to determine any significant differences between the means of the independent groups. Differences were considered to be statistically significant at $p$ values less than 0.05 (Confidence interval 95\%). The relationships among the analysed parameters were investigated using Pearson's correlation coefficient. A $p$ value less than 0.05 was considered statistically significant.

\section{RESULTS}

\section{Effects of hypercholesterolemia, Trihoney and atorvastatin on epididymal weight}

The effects of hypercholesterolemia, Trihoney and atorvastatin on the epididymal weight are illustrated in Figure 1. There was a reduction in the weight of the right and left epididymides in all of the treatment groups apart from the $\mathrm{CH}$ group. The more marked reduction was detected in the DAt group. Compared to the control group, the HCD, DH1 and DAt groups showed significantly lower absolute and relative weights of both right and left epididymides $(p<0.001)$. Among the treatment groups, the $\mathrm{DH} 2$ group exhibited the highest epididymal weight however it remained significantly lower than the control group in the absolute $(p<0.001)$ and relative $(p<0.01)$ weights. The DH2 group demonstrated a significantly higher epididymal absolute weight than the DAt group $(p<0.05)$. There was no significant difference in the epididymal weight between Trihoney received groups and the HCD group $(p>0.05)$.

\section{The correlation between epididymal weight and serum total cholesterol and low-density lipoprotein cholesterol}

The relationships between the epididymal weight and serum TC and LDL-c were illustrated in Table 1 . There was a strong negative correlation between serum TC and the relative $(r=-643$, $p<0.001)$ and absolute $(r=-0.722, \quad p<0.001)$ 
weights of the right epididymis, and between serum TC and the relative $(r=-0.570, p<0.001)$ and absolute $(r=-0.680, p<0.001)$ weights of the left epididymis. Similar pattern of correlations was observed with serum LDL-c in relation to the epididymal weight. A strong negative correlation existed between serum LDL-c and the relative $(r=-0.594, \quad p<0.001)$ and absolute $(r=-0.664$, $p<0.001)$ weights of the right epididymis, and between serum LDL-c and the relative $(r=-0.518$, $p<0.001)$ and absolute $(r=-0.625, \quad p<0.001)$ weights of the left epididymis.

\section{Epididymal gross morphology}

The epididymides of the control and $\mathrm{CH}$ groups were normal in shape and plump in appearance. The epididymides of HCD and DAt groups were smaller in size and pale in colour when compared to the control group. The appearance and size of the epididymides of Trihoney received groups were almost similar to that of the control and $\mathrm{CH}$ groups.
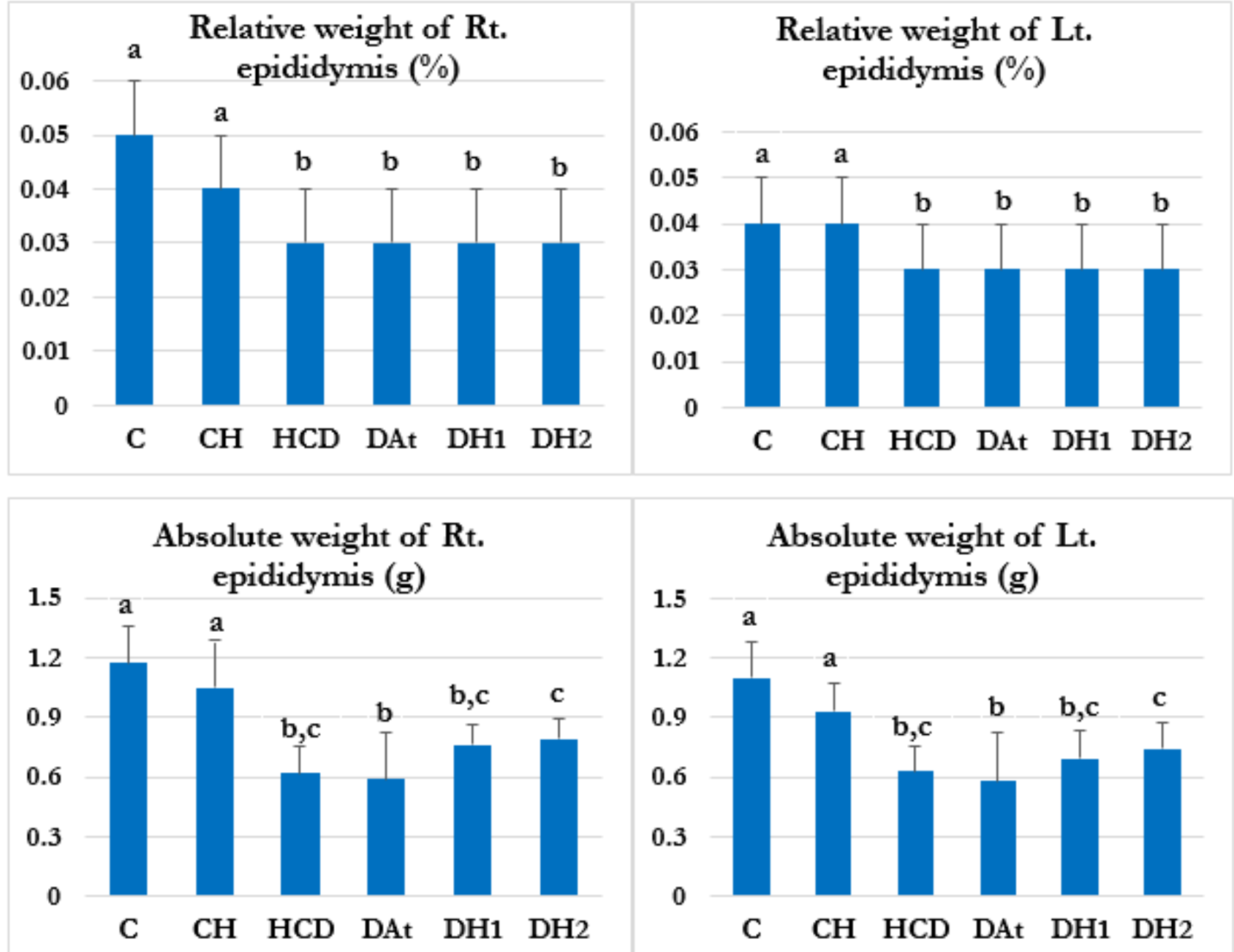

Figure 1. Effects of hypercholesterolemia, Trihoney and atorvastatin on relative and absolute weights of the epididymides. Data were analysed using one-way analysis of variance (ANOVA). A Post Hoc comparison using Tukey HSD test was used to test the significant difference between the groups. a,b,c Values not sharing a common letter differ significantly. C: standard pellet; $\mathrm{CH}$ : standard pellet and 0.6 g/kg/day Trihoney; HCD: 1\% cholesterol diet; DH1: 1\% cholesterol diet and $0.3 \mathrm{~g} / \mathrm{kg} /$ day Trihoney; DH2: $1 \%$ cholesterol diet and $0.6 \mathrm{~g} / \mathrm{kg} /$ day Trihoney; DAt: $1 \%$ cholesterol diet and $2 \mathrm{mg} / \mathrm{kg} / \mathrm{day}$ atorvastatin; Rt: right; Lt: left. 
Table 1. The correlation between epididymal weight and serum total cholesterol and low-density lipoprotein cholesterol.

\begin{tabular}{ccccc}
\hline Organ weight & $\begin{array}{c}\text { Absolute weight } \\
\text { of the Rt. } \\
\text { epididymis }\end{array}$ & $\begin{array}{c}\text { Relative weight of } \\
\text { the Rt. epididymis }\end{array}$ & $\begin{array}{c}\text { Absolute weight } \\
\text { of the Lt. } \\
\text { epididymis }\end{array}$ & $\begin{array}{c}\text { Relative weight of } \\
\text { the Lt. epididymis }\end{array}$ \\
\hline TC $(\mathrm{mmol}$ lipids & $-0.722^{* * *}$ & $-0.643^{* * *}$ & $-0.680^{* * *}$ & $-0.570^{* * *}$ \\
\hline LDL $(\mathrm{mmol} / \mathrm{L})$ & $-0.664^{* * *}$ & $-0.594^{* * *}$ & $-0.625^{* * *}$ & $-0.518^{* * *}$ \\
\hline
\end{tabular}

The correlation between epididymal weight and serum lipid profile was analysed using Pearson's correlation coefficient $(r)$. Total sample for correlation $(N)=42$. TC: total cholesterol; LDL-c: low-density lipoprotein cholesterol; Rt: right; Lt: left. [*** $\mathrm{p}<0.001$ Sig. (2-tailed)].

\section{Histopathological analysis of the epididymis}

\section{Control groups}

Histopathological examination of the epididymal sections from the control and $\mathrm{CH}$ groups revealed normal structure with normal mature sperm within the epididymal tubules. The mature sperm increased from the caput to the cauda (Figures 2-5).

\section{High cholesterol diet group}

The epididymal sections from the HCD group exhibited generalized narrowing of ductal lumina, increased epithelial height, intra-ductal folding of the epithelium and a marked reduction in the number of the mature sperm within the epididymal tubules. There was a widening of the connective tissue areas and a mild increase in the cellular debris in the tubules of the epididymis (Figures 2-5).

\section{Atorvastatin treated group}

Histopathological examination of the epididymal sections from the DAt group demonstrated generalized narrowing of ductal lumina, increased epithelial height, intra-ductal folding of the epithelium, reduced number of the mature sperm with a moderate increase in the cellular debris (Figures 2-5).

\section{Trihoney received groups}

Histopathological examination of the epididymal sections from Trihoney received groups (DH1 and $\mathrm{DH} 2$ ) demonstrated a regained of the normal appearance of the epididymal structure with a highly increased number of sperm inside its tubules. Mature sperm increased from the caput to the cauda. The improvements were more marked in the $\mathrm{DH} 2$ group (Figures 2-5).
Effects of hypercholesterolemia, Trihoney and atorvastatin on epithelial height and diameter of ductal lumens of caput and cauda of the epididymis

The results of the effects of hypercholesterolemia, Trihoney and atorvastatin on the epithelial height and diameter of ductal lumens of the caput and cauda of the epididymis are demonstrated in Figure 6. Feeding of rabbits with 1\% cholesterol diet markedly increased the epithelial height of the caput and cauda of the HCD group $(p<0.001)$ when compared to the control group. Trihoney received groups exhibited a significantly lower epithelial height of the caput and cauda than the HCD group $(p<0.001)$. Meanwhile, they expressed no significant difference from the control group $(p>0.05)$. Atorvastatin treated group (DAt) demonstrated a significant increase in the epithelial height of the caput $(\phi<0.05)$ and cauda $(p<0.001)$ when compared to the control group. The epithelial height of the caput of the atorvastatin treated group was significantly lower than the HCD group $(p<0.01)$ whereas, no significant difference was observed between these two groups in the epithelial height of the cauda $(p>0.05)$. Although the epithelial height of the caput of the DH1 group was lower than that of the DAt group, no significant difference was shown between these two groups. However, the DH1 group showed a significantly lower epithelial height of the cauda than the DAt $(p<0.001)$. The epithelial height of the caput $(p<0.01)$ and cauda $(p<0.001)$ of the DH2 group was significantly lower than the DAt group. As per diameter of ductal lumens of the caput and cauda of the epididymis, the HCD and DAt groups exhibited a marked reduction in the diameter of ductal lumens of the caput and cauda when compared to the control group $(p<0.001)$. There was a significant reduction in the diameter of ductal 
lumens of the caput $(p<0.05)$ and cauda $(p<0.01)$ of the DH1 group when compared to the control group. In comparison to the HCD and DAt groups, the DH1 group showed a significant increase in the diameter of ductal lumens of the caput and cauda $(p<0.001)$. Administration of Trihoney at the dose of $0.6 \mathrm{~g} / \mathrm{kg} /$ day to the DH2 group increased the diameter of ductal lumens of the caput to the level which showed no significant difference from the control group $(p>0.05)$; however, the increase in the diameter of ductal lumens of the cauda remained significantly lower than the control $(p<0.05)$. The DH2 group exhibited a significant increase in the diameter of ductal lumens of the caput and cauda when compared to the HCD and DAt groups $(p<0.001)$. The DH2 group showed a significant increase in the diameter of ductal lumens of the caput when compared to the DH1 group $(p<0.05)$.

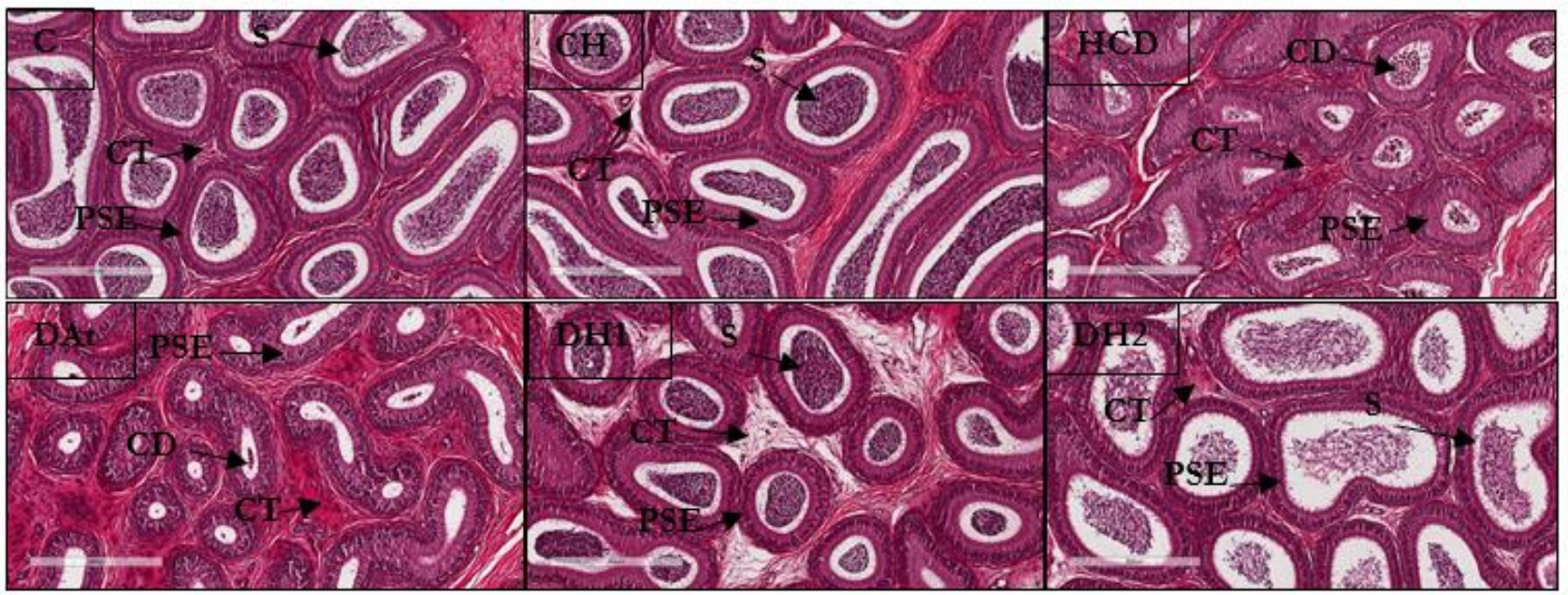

Figure 2. Pictomicrograph of sections of caput of the epididymis stained with Haematoxylin and Eosin stain (scale bar $300 \mu \mathrm{m}$ ). C: standard rabbit pellet group; $\mathrm{CH}$ : standard rabbit pellet with $0.6 \mathrm{~g} / \mathrm{kg} / \mathrm{day}$ of Trihoney; HCD: $1 \%$ cholesterol diet; DAt: $1 \%$ cholesterol diet with $2 \mathrm{mg} / \mathrm{kg} /$ day of atorvastatin; DH1: $1 \%$ cholesterol diet with $0.3 \mathrm{~g} / \mathrm{kg} /$ day of Trihoney; DH2: $1 \%$ cholesterol diet with $0.6 \mathrm{~g} / \mathrm{kg} / \mathrm{day}$ of Trihoney; S: sperm; PSE; pseudostratified epithelium; CD: cellular debris; CT: connective tissue.

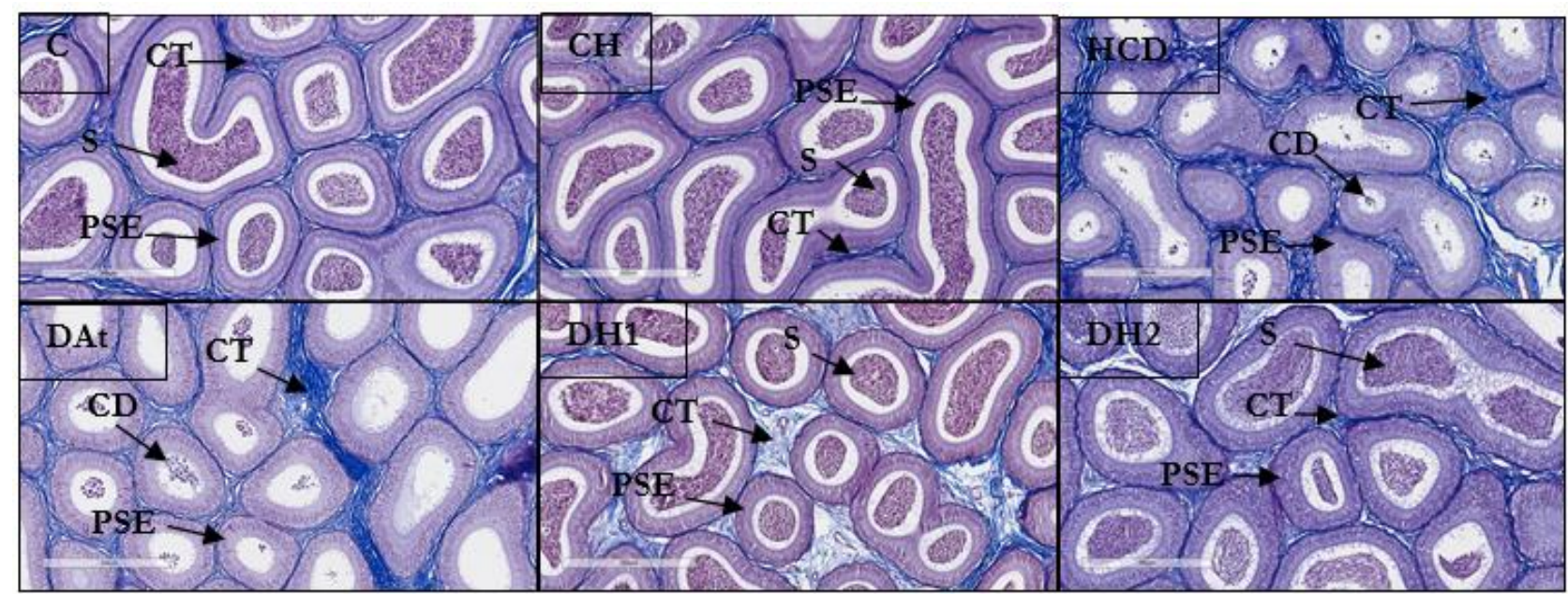

Figure 3. Pictomicrograph of sections of caput of the epididymis stained with Masson's Trichrome stain (scale bar $300 \mu \mathrm{m}$ ). C: standard rabbit pellet group; $\mathrm{CH}$ : standard rabbit pellet with $0.6 \mathrm{~g} / \mathrm{kg} / \mathrm{day}$ of Trihoney; HCD: 1\% cholesterol diet; DAt: $1 \%$ cholesterol diet with $2 \mathrm{mg} / \mathrm{kg} /$ day of atorvastatin; DH1: $1 \%$ cholesterol diet with $0.3 \mathrm{~g} / \mathrm{kg} /$ day of Trihoney; DH2: $1 \%$ cholesterol diet with $0.6 \mathrm{~g} / \mathrm{kg} / \mathrm{day}$ of Trihoney; S: sperm; PSE; pseudostratified epithelium; CD: cellular debris; CT: connective tissue. 


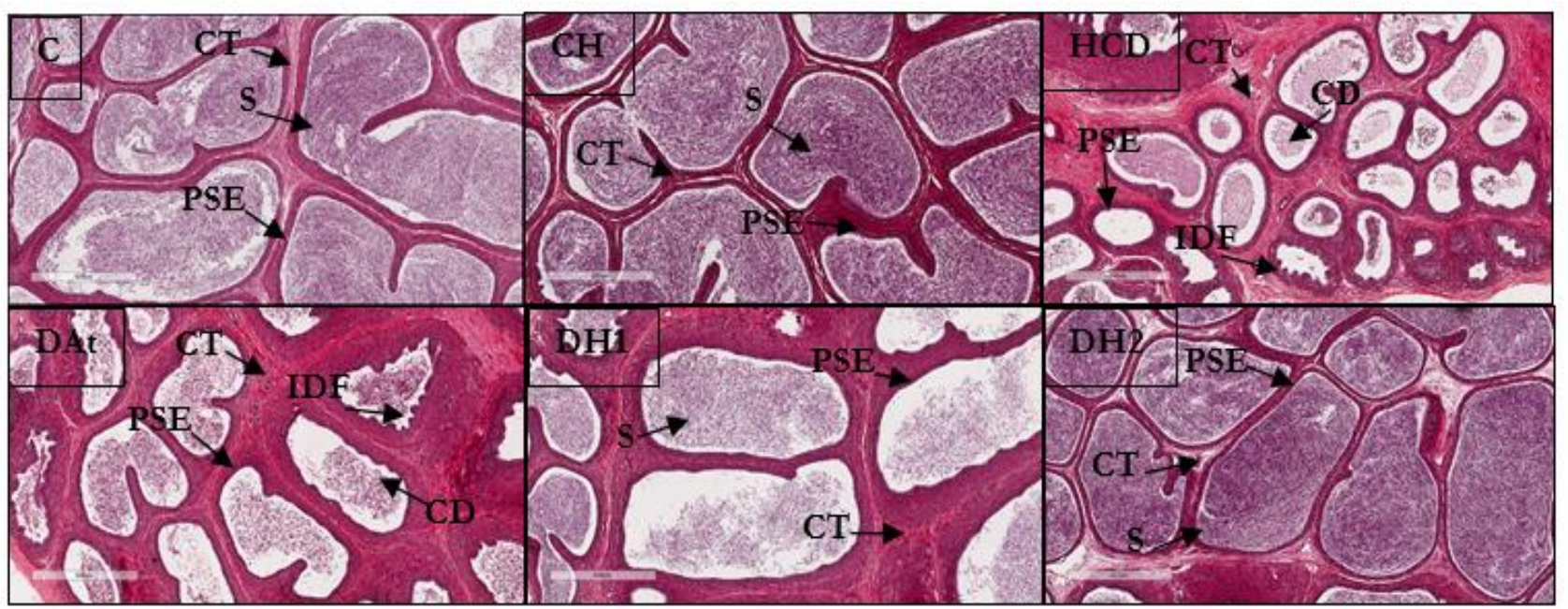

Figure 4. Pictomicrograph of sections of cauda of the epididymis stained with Haematoxylin and Eosin stain (scale bar $600 \mu \mathrm{m}$ ). C: standard rabbit pellet group; $\mathrm{CH}$ : standard rabbit pellet with $0.6 \mathrm{~g} / \mathrm{kg} / \mathrm{day}$ of Trihoney; HCD: $1 \%$ cholesterol diet; DAt: $1 \%$ cholesterol diet with $2 \mathrm{mg} / \mathrm{kg} /$ day of atorvastatin; DH1: $1 \%$ cholesterol diet with $0.3 \mathrm{~g} / \mathrm{kg} /$ day of Trihoney; DH2: $1 \%$ cholesterol diet with $0.6 \mathrm{~g} / \mathrm{kg} / \mathrm{day}$ of Trihoney; S: sperm; PSE; pseudostratified epithelium; CD: cellular debris; CT: connective tissue. IDF: intra-ductal folding of epithelium.

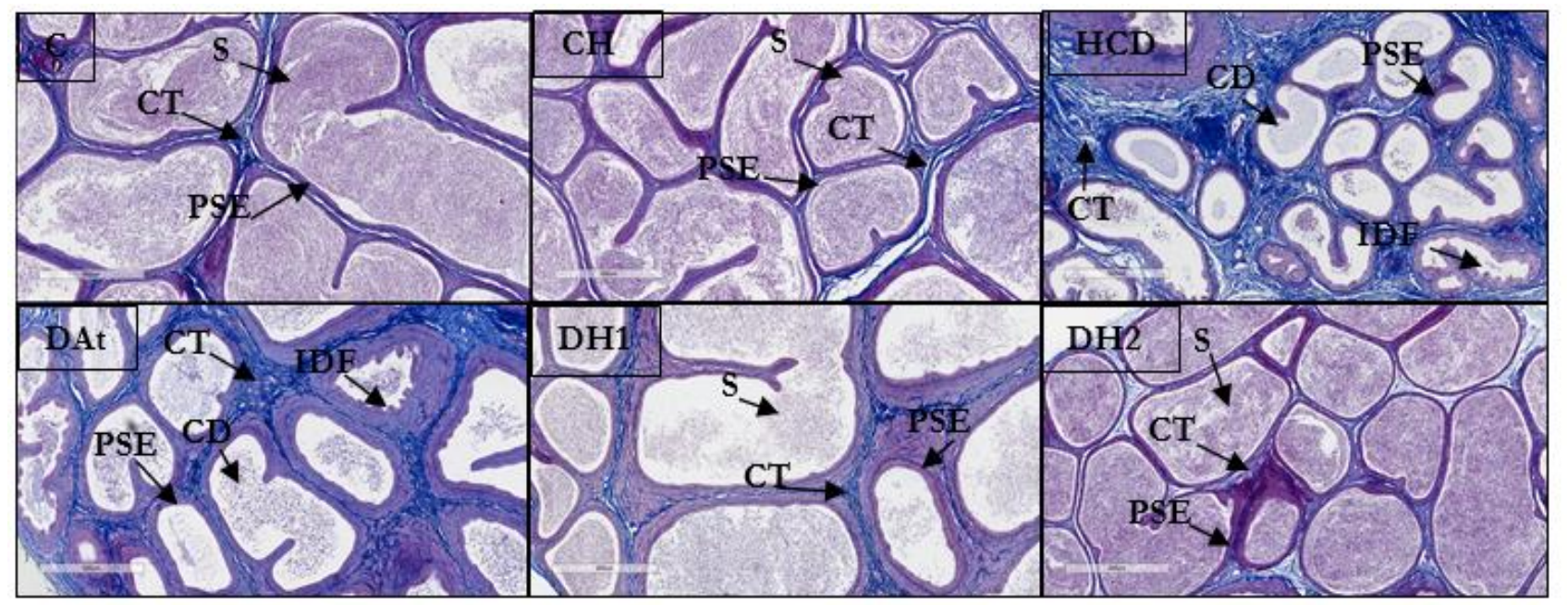

Figure 5. Pictomicrograph of sections of cauda of the epididymis stained with Masson's Trichrome stain (scale bar $600 \mu \mathrm{m})$. C: standard rabbit pellet group; $\mathrm{CH}$ : standard rabbit pellet with $0.6 \mathrm{~g} / \mathrm{kg} / \mathrm{day}$ of Trihoney; HCD: $1 \%$ cholesterol diet; DAt: $1 \%$ cholesterol diet with $2 \mathrm{mg} / \mathrm{kg} /$ day of atorvastatin; DH1: $1 \%$ cholesterol diet with $0.3 \mathrm{~g} / \mathrm{kg} /$ day of Trihoney; DH2: $1 \%$ cholesterol diet with $0.6 \mathrm{~g} / \mathrm{kg} / \mathrm{day}$ of Trihoney; S: sperm; PSE; pseudostratified epithelium; CD: cellular debris; CT: connective tissue. IDF: intra-ductal folding of epithelium. 

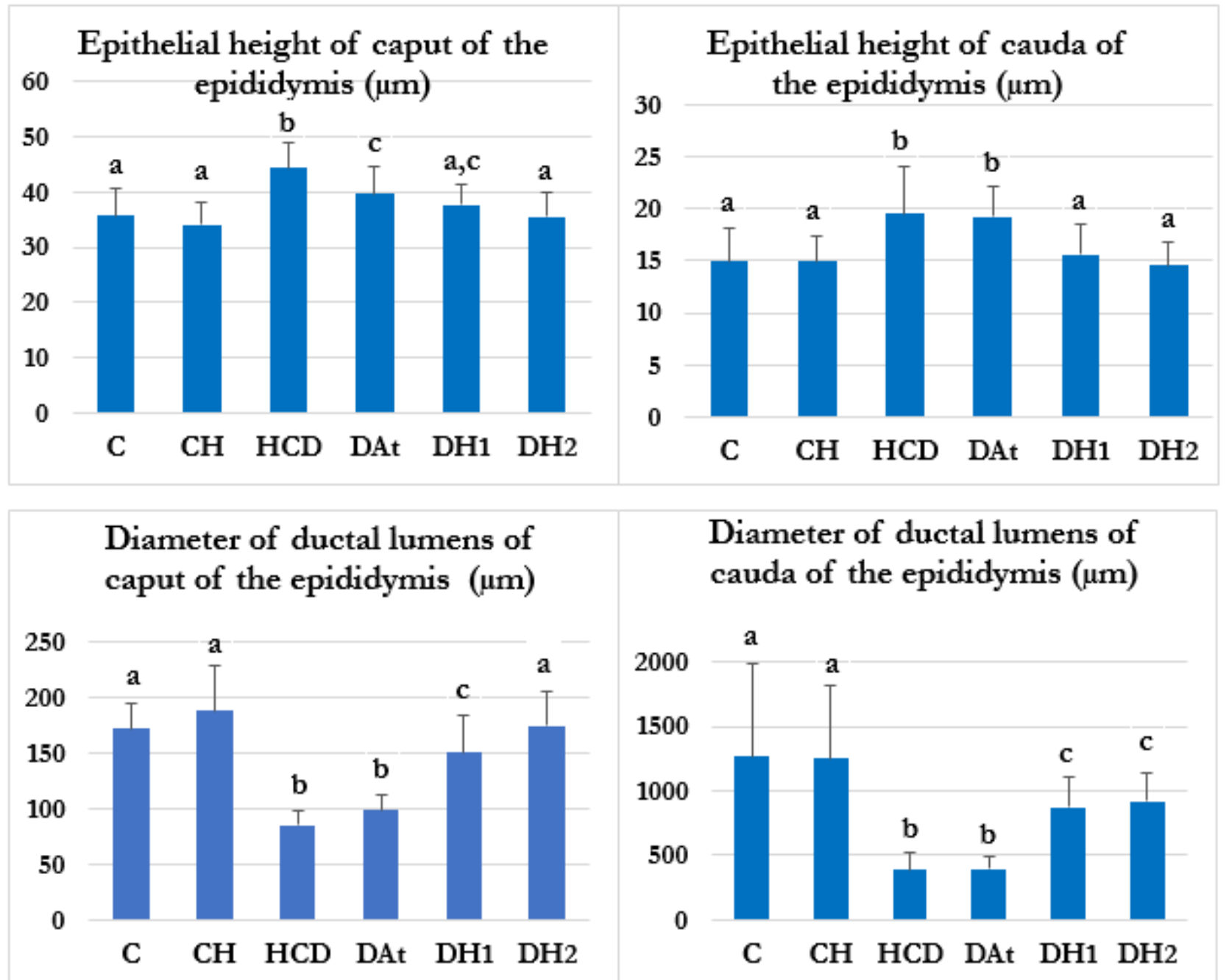

\section{Diameter of ductal lumens of cauda of the epididymis $(\mu \mathrm{m})$}

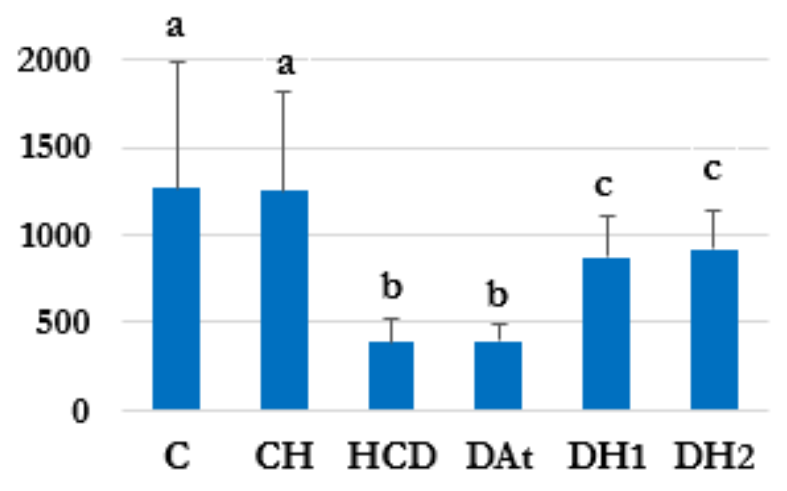

Figure 6. Effects of hypercholesterolemia, Trihoney and atorvastatin on epithelial height and diameter of ductal lumens of caput and cauda of the epididymis. Data were analysed using one-way analysis of variance (ANOVA). A Post Hoc comparison using Tukey HSD test was used to test the significant difference between the groups. a,b,c Values not sharing a common letter differ significantly. C: standard pellet; $\mathrm{CH}$ : standard pellet and $0.6 \mathrm{~g} / \mathrm{kg} /$ day Trihoney; HCD: 1\% cholesterol diet; DH1: $1 \%$ cholesterol diet and 0.3 $\mathrm{g} / \mathrm{kg} /$ day Trihoney; DH2: $1 \%$ cholesterol diet and $0.6 \mathrm{~g} / \mathrm{kg} /$ day Trihoney; DAt: $1 \%$ cholesterol diet and $2 \mathrm{mg} / \mathrm{kg} /$ day atorvastatin.

\section{DISCUSSION}

The current study demonstrated that feeding of rabbits with $1 \%$ cholesterol diet either alone or in combination with atorvastatin caused a significant reduction in the epididymal weight and epididymal atrophy. Supplementation of Trihoney particularly at the dose of $0.6 \mathrm{~g} / \mathrm{kg} /$ day improved epididymal weight, regained the normal histology of the epididymis and increased the number of the mature sperm inside the tubules of the epididymis.
Feeding of rabbits with $1 \%$ cholesterol diet in the present study reduced epididymal weight significantly. In agreement with this result, Alzubaidi \& Diwan. (2013) reported a reduction in the relative epididymal weight in rats fed with $1.5 \%$ cholesterol diet for 4 weeks. The main causes of epididymal weight reduction are reduced sperm content and contraction of ductal lumen size which caused by disruption of spermatogenesis and reduced sperm production or release from the testes (Creasy \& Chapin, 2013). Histologically, hypercholesterolemic rabbits in the current study exhibited epididymal 
atrophy evidenced by generalized narrowing of ductal lumina and intra-ductal folding of the epithelium associated with an increase in the epithelial height, marked reduction in the number of the mature sperm and an increase in the cellular debris within the tubules of the caput, corpus and cauda of the epididymis. The presence of sloughed germ cells and cellular debris in the epididymal tubules is an important indicator of testicular damage (Creasy \& Chapin, 2013). The main causes of epididymal atrophy are reduced sperm and fluid output from the testes or reduced androgen support (Creasy et al., 2012). In a previous study, administration of cholesterol at a dose of $400 \mathrm{mg} / \mathrm{kg} /$ day to rats for 2 months resulted in a reduction of the epithelial height of the cauda of the epididymis coupled with an enlarged lumen devoid of sperm (Purohit \& Daradka, 1999). Administration of the same dose (400 $\mathrm{mg} / \mathrm{kg} /$ day) for the same duration (2 months) to rats in another study caused a reduction of the epithelial cell height of the caput and cauda of the epididymis accompanied by a reduction of sperm density in the cauda (Bataineh \& Nusier, 2005). The increase in the epithelial height of the epididymis in the present study is likely caused by the direct toxic effect of hypercholesterolemia on the epididymis rather than androgen deprivation which causes reduction in the epithelial height of the epididymis (De Grava Kempinas \& Klinefelter, 2014). In LXR; $\beta^{-1}$ mice, administration of $1.25 \%$ cholesterol diet for 4 weeks induced histopathological alterations in the caput of the epididymis manifested by absence of luminal cilia, reduced epithelial height and lipid accumulation in the smooth muscle cells lining of the caput epididymal tubules. It was suggested that the epididymis might be affected earlier than the testes upon consumption of dietary cholesterol overload (Ouvrier et al., 2011).

In the current study, treatment of rabbits with atorvastatin failed to counteract the negative impacts of hypercholesterolemia on epididymal weight and histopathology. The negative impact of atorvastatin on the epididymal weight was reported previously in rats (Niederberger, 2005). It was also reported to cause aplasia and aspermia in rats' epididymis. However, no adverse effects were induced by atorvastatin on the histology of the reproductive organs of dogs (Niederberger,
2005). Intake of atorvastatin by normocholesterolemic men significantly affects epididymal functional markers $(\alpha$-glucosidase and L-carnitine) and live sperm proportion (PonsRejraji et al., 2010).

Trihoney supplementation particularly at the dose of $0.6 \mathrm{~g} / \mathrm{kg} /$ day increased the epididymal weight when compared to the administration of $1 \%$ cholesterol diet either alone or in combination with atorvastatin but without statistical significance. It regained the normal appearance of the epididymal structure with a highly increase in the number of sperm inside its tubules. While Mohamed et al., (2012) revealed that no significant change in the epididymal weight was induced by honey consumption, Abdul-Ghani et al. (2008) and Oyelowo et al. (2014) reported that honey supplementation to rats increased epididymal weight significantly. To the best of our knowledge, no previous study has been undertaken to investigate the beneficial effects of honey on the epididymal histology. However, numerous previous studies have been conducted to evaluate the effects of honey as either a fertility enhancing and potentiating natural product or to detect the importance of honey in the attenuation of the impacts of various toxicants on the other reproductive organs mainly the testes (Michael et al., 2015; Mohamed et al., 2012; Syazana et al., 2011). The improvement in the epididymal weight and histopathology via Trihoney administration could be through the enhancement of spermiogenesis and spermatogenesis which attributed to the synergistic antioxidant property of honey nutritional constituents (Abdul-Ghani et al., 2008; Mohamed et al., 2011; Mohamed et al., 2012; Syazana et al., 2011). It could also be through the elevation of testosterone that is likely due to the antioxidant activities of honey (Kenani et al., 2015; Michael et al., 2015). These mechanisms are compatible with Trihoney that has high total phenolic components and high free radical scavenging activity. There could be other mechanisms for Trihoney through a direct effect on the epididymis rather than an effect on the testicular tissue. 


\section{CONCLUSION}

Trihoney exhibited its potential health benefit as a protective agent against epididymal weight reduction and histopathological alterations in hypercholesterolemic male rabbits. Further studies are required to explore the exact underling mechanisms of Trihoney in the protection against hypercholesterolemia-induced epididymal changes. Additionally, future studies investigating the possible harmful effects of atorvastatin on male reproductive system and fertility are of high importance.

\section{REFERENCES}

Abdul-Ghani, A. S., Dabdoub, N., Muhammad, R., Abdul-Ghani, R., \& Qazzaz, M. 2008. Effect of Palestinian honey on spermatogenesis in rats. Journal of Medicinal Food 11(4): 799_ 802.

Alzubaidi, N. A. K. \& Diwan, M. A. A. 2013. The effect of taurine on reproductive efficiency in male rats fed high cholesterol diet. Basrah Journal of Veterinary Research 12(1): 30-40.

Anderson, A. L., Stanger, S. J., Mihalas, B. P., Tyagi, S., Holt, J. E., McLaughlin, E. A., \& Nixon, B. 2015. Assessment of microRNA expression in mouse epididymal epithelial cells and spermatozoa by next generation sequencing. Genomics Data 6: 208-211.

Ashrafi, H., Ghabili, K., Alihemmati, A., Jouyban, A., Shoja, M., Aslanabadi, S., ... Hajhosseini, L. 2013. The effect of quince leaf (Cydonia oblonga miller) decoction on testes in hypercholesterolemic rabbits: A pilot study. African Journal of Traditional, Complementary and Alternative Medicines 10(2): 277-282.

Bataineh, H. N. \& Nusier, M. K. 2005. Effect of cholesterol diet on reproductive function in male albino rats. Saudi Medical Journal 26(3): 398-404.

Bustan, A. \& Jawad, A. 2017. The effect of two types of statins (rosuvastatin and atorvastatin) on the fertility of male and female mice. British Journal of Medicine and Medical Research 19(12): 1-11.

Creasy, D., Bube, A., Rijk, E. de, Kandori, H., Kuwahara, M., Masson, R., ... Whitney, K. 2012. Proliferative and nonproliferative lesions of the rat and mouse male reproductive system. Toxicologic Pathology 40(6S): 40S-121S.

Creasy, D., Cartwright, J., Moreland, S., Willoughby, C., Collier, M., \& Odum, J. 2008. Endocrine disruption: a guidance document for histologic evaluation of endocrine and reproductive tests.

Creasy, D. M. 2001. Pathogenesis of male reproductive toxicity. Toxicologic Pathology 29(1): 64-76.

Creasy, D. M. \& Chapin, R. E. 2013. Male Reproductive System. In Haschek and Rousseaux's Handbook of Toxicologic Pathology Third ed. pp. 2493-2598. USA: Elsevier Inc., Academic Press.

De Grava Kempinas, W. \& Klinefelter, G. R. 2014. Interpreting histopathology in the epididymis. Spermatogenesis 4(2): e979114-1-e979114-12.

Du, B., Xu, G., Cao, H., Cui, W., Lin, S., Liu, Y., \& Qin, L. 2013.
Effects of atorvastatin on expression of ICAM-1 in atherosclerotic rabbits. Journal of Cardiovascular Medicine 14(2): 120-126.

Galaly, S. R., Hozayen, W. G., Amin, K. A., \& Ramadan, S. M. 2014. Effects of Orlistat and herbal mixture extract on brain, testes functions and oxidative stress biomarkers in a rat model of high fat diet. Beni-Suef University Journal of Basic and Applied Sciences 3(2): 93-105.

Ibrahim, M., Ahmed, I. A., Mikail, M. A., Ishola, A. A., Draman, S., Isa, M. L. M., \& Yusof, A. M. 2017. Baccaurea angulata fruit juice reduces atherosclerotic lesions in diet-induced Hypercholesterolemic rabbits. Lipids in Health and Disease 16(1): 134.

Inoue, K., Murayama, S., Seshimo, F., Takeba, K., Yoshimura, Y., \& Nakazawa, H. 2005. Identification of phenolic compound in manuka honey as specific superoxide anion radical scavenger using electron spin resonance (ESR) and liquid chromatography with coulometric array detection. Journal of the Science of Food and Agriculture 85(5): 872-878.

Jorge, P. A. R., Almeida, E. A. De, Ozaki, M. R., Jorge, M., \& Carneiro, A. 2005. Effects of atorvastatin, fluvastatin, pravastatin, and simvastatin on endothelial function, lipid peroxidation, and aortic atherosclerosis in hypercholesterolemic rabbits. Arquivos Brasileiros de Cardiologia 84(4): 314-319.

Kenani, M., Rajabzadeh, A., Saki, G., Khodadadi, A., Sarkaki, A., Jafai, A., \& Hemadi, M. 2015. A survey of the relationship between noised pollution, honey and vitamin $\mathrm{E}$ and plasma level of blood sexual hormones in noise-exposed rats. Jentashapir Journal of Health Research 6(1): 1-5.

Leary, S., Underwood, W., Anthony, R., Cartner, S., Corey, D., Grandin, T., ... Patterson-kane, E. 2013. AVMA Guidelines for the Euthanasia of Animals. Schaumburg: American Veterinary Medical Association.

Michael, M., Anyakudo, C., Balogun, A. J., \& Adeniyi, M. O. 2015. Beneficial effects of honey-based diet on glycemic control and reproductive potential in diabetic rats. World Journal of Nutrition and Health 3(2): 41-46.

Mohamed, M., Sulaiman, S. A., Jaafar, H., \& Sirajudeen, K. N. S. 2012. Effect of different doses of Malaysian honey on reproductive parameters in adult male rats. Andrologia 44: 182-186.

Mohamed, Mahaneem, Sulaiman, S. A., Jaafar, H., \& Sirajudeen, K. N. S. 2011. Antioxidant protective effect of honey in cigarette smoke-induced testicular damage in rats. International Journal of Molecular Sciences 12(9): 5508-5521.

Mohamed, Z. B. H., Abdulsalam, H., Alfarisi, H., Abdullah, N. Z., Harun, N., Muhammad, N., \& Abdul Rahim, R. 2017. Renoprotective role of tualang honey against high cholesterol diet induced acute kidney diseases in an animal model. Journal of Applied Pharmacentical Science 7(12): 97-101.

Niederberger, C. 2005. Atorvastatin and male infertility: is there a link? Journal of Andrology 26(1): 12.

Nweze, J. A., Okafor, J. I., Nweze, E. I., \& Nweze, J. E. 2016. Comparison of antimicrobial potential of honey samples from Apis mellifera and two stingless bees from Nsukka, Nigeria. Journal of Pharmacognosy \& Natural Products 02(04): $1-7$

Ouvrier, A., Alves, G., Damon-Soubeyrand, C., Marceau, G., Cadet, R., Janny, L., Saez, F. 2011. Dietary cholesterolinduced post-testicular infertility. Plos One 6(11): 1-13.

Oyelowo, O. T., Adekunbi, D. A., \& Dada, K. A. 2014. Protective role of Nigerian honey on sperm indices and testis in sucrose-fed rats. Bangladesh Journal of Medical Science 13(2): 180-189.

Pons-Rejraji, H., Sion, B., Brugnon, F., Artonne, C., Gouby, G., Grizard, G., Tauveron, I. 2010. Effects of atorvastatin on male fertility. Endocrine Abstracts, 12th European Congress of 
Endocrinology, 22, 526.

Purohit, A. \& Daradka, H. M. M. 1999. Effect of mild hyperlipidaemia on testicular cell population dynamics in albino rats. Indian Journal of Experimental Biology 37(4): 396398.

Pyrzynska, K. \& Biesaga, M. 2009. Analysis of phenolic acids and flavonoids in honey. Trends in Analytical Chemistry 28(7): 893-902.

Reagan-Shaw, S., Nihal, M., \& Ahmad, N. 2007. Dose translation from animal to human studies revisited. The FASEB Journal 22(3): 659-661.

Sandella, B., Hartmann, B., Berkson, D., \& Hong, E. 2012. Testicular conditions in athletes: torsion, tumors, and epididymitis. Current Sports Medicine Reports 11(2): 92-95.

Soltani, Y., Aklil, B., Mokrani, Z., Hamouli, Z., \& F, H. B. 2013. Effects of diet induced obesity on the gonadal axis in the male rabbit: impact of leptin. USTHB-FBS-4th International Congress of the Populations \& Animal Communities "Dynamics \& Biodiversity of the Terrestrial \& Aquatic Ecosystems'"'CIPCA4"TAGHIT (Bechar) - ALGERLA, 478487.

Song, X., Liu, H., Wang, X., Li, Z., \& Huang, C. 2014. Atorvastatin combined with poly-unsaturated fatty acid confers better improvement of dyslipidemia and endothelium function. Lipids in Health and Disease 13(186): 1-5.

Syazana, N. S., Hashida, N. H., Majid, A. M., Durriyyah Sharifah, H. A., \& Kamaruddin, M. Y. 2011. Effects of Gelam honey on sperm quality and testis of rat. Sains Malaysiana 40(11): 1243-1246.

Zhao, X.-H., Qiu, J.-H., Cai, W.-Q., Li, S., \& Li, W. 2013. Preparation of infertile male rabbits by local electron beam irradiation for intratesticular transplantation of autologous bone marrow stem cells. Acta Cirurgica Brasileira 28(2): 148153. 